\title{
THE INTANGIBLE ASSETS ADVANTAGES IN THE MACHINE VISION INSPECTION OF THERMOPLASTIC MATERIALS
}

\author{
MUNTEAN Diana \\ Ph.D. student, Faculty of Engineering / Department Industrial Engineerig, "Lucian Blaga" University of \\ Sibiu,Romania,diana.muntean@ulbsibiu.ro \\ RĂULEA Andreea Simina \\ Ph.D. student, Faculty of Engineering/Department Engineering and Management, "Lucian Blaga" \\ University of Sibiu, Romania, andreea.raulea@ulbsibiu.ro
}

\begin{abstract}
Innovation is not a simple concept but is the main source of success. It is more important to have the right people and mindsets in place than to have a perfectly crafted plan in order to make the most out of an idea or business. The aim of this paper is to emphasize the importance of intangible assets when it comes to machine vision inspection of thermoplastic materials pointing out some aspects related to knowledge based assets and their need for a success idea to be developed in a successful product.
\end{abstract}

Key words: intangible assets, intellectual capital, thermoplastic materials, machine vision inspection.

\section{Introduction}

Nowadays, innovation is considered the main driver of globalised success, radical (basic or fundamental) vs. incremental (improvement), and disruptive vs. sustaining (sequential and/or complementary). Other important types of (non-technological) innovations that do not result from scientific and/or technological $R \& D$, but are often crucial for profitably marketing the products and services resulting from the investment made in $R \& D$ are: marketing innovation, institutional innovation, and complementary innovation.

In the present moment it is generally accepted that in a knowledge-driven, competitive business environment, technological innovation is a principal determinant of successful firm performance and long term competitive advantage. Technological innovation is one of the most used types of innovation and may be classified in several ways: product vs. process.

Managing innovation better than its competitors is one of the main objectives of a business that wishes to survive and thrive in today's economy. So, in order to achieve that, the main goal must be to innovate. For most technology-based enterprises, a successful invention results in a more efficient way of doing things or in a new commercially viable product. The improved profitability of the enterprise is the outcome of added value that underpins a bigger stream of revenue or higher productivity.

For an idea, for example the one discussed in this article (machine vision inspection of thermoplastic materials) that may result in a patentable invention, the ultimate choice between the use of either the trade secret route or the patent route for protecting it should be seen as a strategic business decision that should be taken only at a later stage of its development when all the requirements of patentability are met, namely, statutory subject matter, novelty, inventive step/non-obviousness, capable of industrial application, and adequate disclosure. At that stage, the choice would depend on the nature of the invention, its business potential, the nature of competition, the possibility of its independent creation by competitors and the ability of competitors to reverse engineer it easily from the product developed by using it. But before analyzing that, it should be taken into consideration to analyze several indicators used to measure the efforts of an enterprise in undertaking research on and developing innovative ideas. These include, expenditure on research and development, information on innovation, total sales, firm size, innovation strategies, etc. These indicators are directly or sometimes indirectly influenced by intellectual property. The intellectual property tools used during the 
"conception of an innovative idea" stage continues to be relevant also during this stage.

For, example, given the fact that research and development plays an important role at organizational level but also at national level, Romania situation should be analyzed. As can be seen in the figure below, Romania is performing well below the average of the EU on all dimensions and all indicators. The weakest relative performance in terms of dimensions is Linkages and entrepreneurship, while in terms of indicators, the worst relative performance is observed for PCT patent applications in societal challenges and PCT patent applications. Romania performs similar to the EU average for a number of indicators, in particular Youth with upper secondary level education, Exports in medium \&
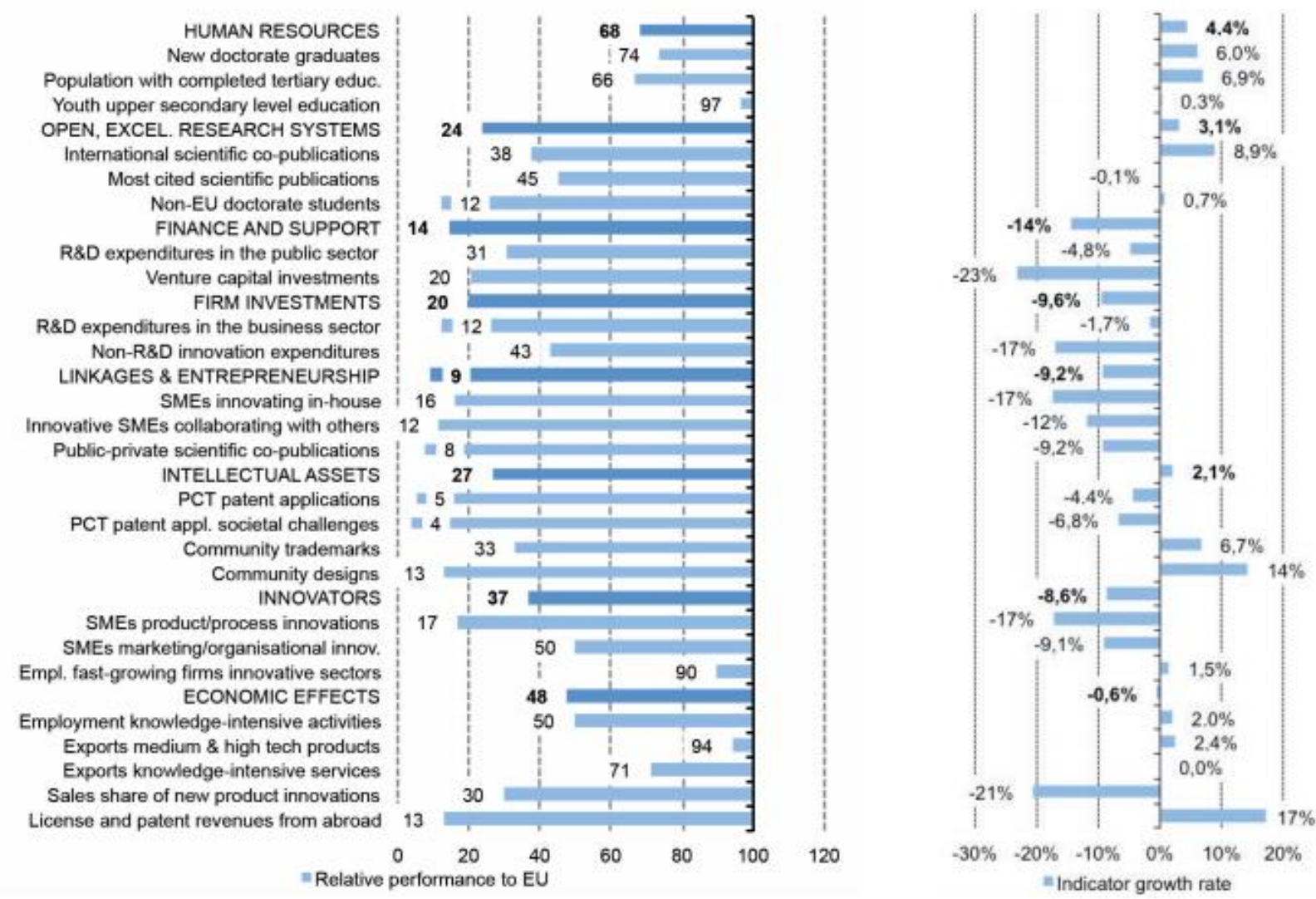

high tech products, and Employment in fast-growing firms in innovative sectors. Performance has increased the most for the innovation dimension Human resources (4.4\%). High growth at the indicator level is observed for License and patent revenues from abroad (17\%) and Community designs (14\%). The strongest declines in performance are observed in Venture capital investments (-23\%), Sales share of new product innovations (-21\%), Non-R\&D innovation expenditures (-17\%), SMEs innovating inhouse $(-17 \%)$, and SMEs with product or process innovations $(-17 \%)$.

Figure 1: Romania Innovation Scoreboard 2016

Source: European Innovation Scoreboard 2016

\section{Knowledge-based capital and the importance to new product development}

Knowledge-based capital also know as intangible assets or intellectual capital, constitutes a long-lasting resource for companies and institutions. Knowledge based assets are not physical in nature and their main value stems from their knowledge content and their ability to add value to other assets.

Following a widely used classification proposed by Corrado et al. [1], investment in knowledge-based capital can be subdivided into three main groups: computerised information (e.g. software and databases); innovative property (e.g. scientific and non-scientific R\&D, copyrights, designs and trademarks); and economic competencies (including brand equity, aspects of advertising 
and marketing, firm-specific human capital, and organisational know-how and capabilities). Some based capital types have recently been recognised by the international statistical community as capital assets and are now accounted for in the System of National Accounts (SNA), underlining their importance. Knowledge-based capital assets consistent with the SNA definition include: software, $\mathrm{R} \& \mathrm{D}$, entertainment, literary and artistic originals, and mineral exploration. Other knowledge based capital assets such as design, new product development in the financial industry, brands, firm-specific training and organisational capital have in recent years been at the centre of methodological work aimed at measuring these assets in an internationally comparable way.

While much has been done to underpin these new sources of growth, future measurement work will need to address the pricing of these assets, the rate at which they depreciate, and the extent to which investment in different assets overlap. As firms within and across industries differ in their investment behaviors, additional work will be needed to measure and study investment patterns at the firm and industry levels. Such efforts will help to inform policy design to leverage these sources of growth, their specificities and their complementarities.

The importance of knowledge-based capital for productivity and economic growth has been widely recognized. Some organizations are investing as much or more in knowledge-based capital as they do in physical capital (machinery, equipment and buildings). For example, in 2013, in the United States and the United Kingdom, investment in all types of knowledge-based capital amounted to about 1.5 times investment in fixed assets. In contrast, investment in knowledge-based capital in countries such as Italy and Spain amounted to less than half of investment in fixed assets. This proportion increased to about $80 \%$ in France and Germany and to about $90 \%$ or more in Denmark and Sweden. These investment patterns mirror the industrial structure of economies and differences in the knowledge intensity of sectors. Two main trends emerge when comparing 1995 and 2013 industryspecific knowledge-based capital investment patterns: all sectors saw their median knowledge capital intensity increase, confirming the total business sector trends, and these increases were more heterogeneous, as indicated by the greater differences shown in the sector-specific intensities of top and bottom quartiles [2].



Figure 2: Knowledge capital intensity by sector, 1995 and 2013

Source: OECD calculations based on INTAN-Invest data, www.intaninvest.net and OECD, Structural Analysis (STAN) Database, http://oe.cd/stan, June 2015.

As can be seen in the figure 1, knowledge capital in the manufacturing sector has grown. The same is emphasized in the study, made by Goodridge [3] who provide evidence that the ratio of intangible investment to value added is highest in the manufacturing sector in the UK. This finding was corroborated by Niebel [4] for a larger set of 10 European countries. 


\section{Thermoplastic materials and there flaws}

Thermoplastic materials are materials that are widely used in automobile industry, they are obtained in different ways, after their utility, so the processes for the plastic manufacturing are extrusion, injection, calendar, thermoforming, blowing, and others, but the process of injecting is an interesting way to obtain thermoplastic parts, it is situated on the two global ranking after extrusion in the manufacturing process of the automobile products.

Plastic materials are not natural materials, but are organic materials, inorganic or have a mixed nature, composed of long chains of molecules (containing between 103 and 106 atoms), known as polymers, that are formed by joining the chain of two or more molecules of the monomer process called polymerization.

History plastics dates from 1736 when French naturalist Charles-Marie discovers in Peru the rubber tree. But the age of plastics dates between 1920-1940, when in 1909 the Belgian Backelan discovers the first synthetic material that is Bakelite. [5]

The strength of these materials to the inorganic acids and other chemical agents, electrical insulating and good thermal properties, low weight and easy handling, made of plastic material the material that can replace a large part of the use of metallic materials in our time. Other important factor in using parts from plastic is that during the processing of thermoplastics, material under heat and pressure, undergoes a reversible chemical transformation, that makes them to be recyclable.

The parts we encounter in building industry automotive products injected are the pieces from the outside elements of the car like headlights, side mirrors, etc., and the elements that are part of the interior of the car, as for example: buttons.

All this kind of thermoplastic parts obtained by injection processes can have flaws that are those imperfections that affect the functionality and look. So, molded parts flaws, are the result of a single or complex cause of actions that two faults with a different appearance may have one or more common causes. Achieving injection molded parts, a high quality parts with minimum flaws is subject to manufacturing technology plan drawn up and how such permission is respected. Manufacturing technology can have certain anomalies in the beginning, but is improving constantly throughout the process of injecting plastics.

The thermoplastic parts imperfections can be classified as geometrical flaws, when the flaws are related to the drawing of the parts, structural flaws, that are the defects related to the composition of the material which are the parts made and surface flaws, that are the defects linked to the outside of the part.

In figure 3, the defect part is a button, that has a geometrical flaw, a burr. This type of defect is the most common imperfection in molded parts. This flaw is due too large gaps in the mold caused by too small closing pressure, too low rigidity of the mold, closing the mold surfaces wear or failure tends to occur due to the improper injection parameters. Burrs occur near joints, sealing faces, the ventilation channels. Small burrs often are not immediately visible, but on the large surfaces, burrs are thick, sometimes leaving a few centimeters outside the nominal profile. [6]



Figure: 3 Burrs on a rotary button Source: http://www.arburg.com 
Identifying product flaws can be done either by direct observation of the parts or using a high inspection system that can give a precise description. Too identify imperfect parts, technological innovation is needed, a type of innovation that can inspect a part wherever is it in the process and can give a situation about is status, ok or not ok, pass or failed, that kind of innovation that revolutionized the inspection manufacture process of the part.

So, more and more companies see innovation as the heart of their growth strategy and seek ways to improve their activities. Intangible assets contributes to the renewal of the firm through its dynamic and reciprocal relation with the firm's competences.

\section{Manual visual inspection versus automatic visual inspection system}

Because during the manufacturing process may appear errors, flaws, is necessary to monitorize the activities required in product execution, a supervision that must ensure that the conditions of work and design are meet.

Manual visual inspection is part of the quality, and consist of using skilled human operators and the use of optical microscopes for detection errors. The eye can detect the accuracy of the size, shape, color, brightness, contrast, texture, depth and grain of material. This type of inspection is used in various industries such as automotive industry, aviation industry, pharmaceutical industry, etc.

Manual visual inspection, is the simplest method used in auto parts manufacturing production. It can use optical measurement instruments like: magnifying glass, endoscope, microscope, etc.

Manual visual inspection requires skilled human operators or, in other words, the intangible assets incorporated in human resources knowledge. So, the human resource management has the role to ensure that the organization has the intellectual capital it needs in order to ensure a high quality product inspection.

The second type of inspection that we can use is automatic visual inspection (AVI) that is a technique of image processing for quality control and automatic production line.



Figure: 4 Visual inspection program created in Vision Builder for Automated Inspection

AVI conventional systems operates camera views with images that are found in the library testing machine as a template, to measure the difference between a predefined pattern and an image captured by the camera. AVI was developed decades; the system can detect the same type of surface defect. Objections production is inspected by the sensor and visual information will be taken and the system will return for analysis. The inspection process usually includes measurement of the whole, and the geometric dimensions of the surface. [7]

In figure 4, is seen an example of a visual inspection program, where the camera inspection process starts with an image capture of the piece to be processed. The delay button is used to set a new image capture after the time span. After that we select the coordinate system that ensures all measurements move with the object in the field of inspection camera. The obtion to detect objects is used for classify, to identify an unknown object by comparing its significant features with a set of particularities that represent the sample. The analysis used is a geometric analysis that creates an inspection that measures the distance between the holes. In the end, inspection status determine if the part passed by the stages to which it was inspected or droppes to one of them. When a part is considered dropped, not in the parameters, the FAIL screen appears on the test screen, and if the part is good, PASS appears at the end of the program.

An example of automatic visual inspection part is seen in figure 5, where was taken a capture imagine of a part that has three symbols of three different buttons. Here the software compares the 
pixels number of the image taken, to a template saved in the software library, and takes a decision. In this case, the third button has a red frame that indicates that the symbol it's not ok.

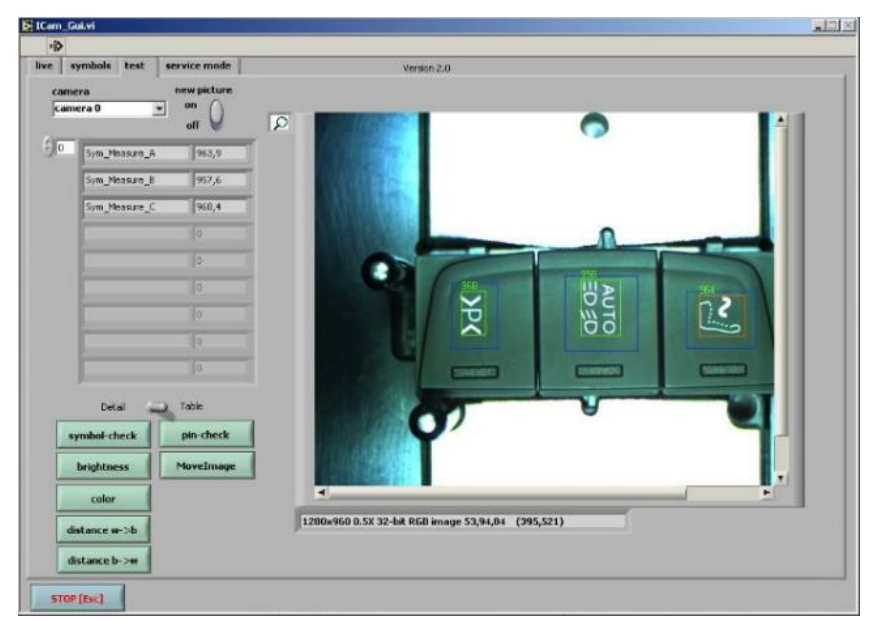

Figure 5: Symbol inspection on buttons

In fact, a machine vision has a virtual instrument VI that replaces traditional physical measurement devices by software modules with a universal interface $\mathrm{I} / \mathrm{O}$. Visual inspection is a modern branch of implementing image processing algorithms view of industrial machines. [8] Machine view eliminates human errors in the inspection of the product and cause productivity to be more effective.

Manufacturing companies heavily rely on their capital assets to generate revenues and profits. A capital asset can be tangible or intangible

\section{Conclusions}

The strength of the machine vision inspection is a financial profit, because this technical method reduces production costs since the beginning of production process of the part because, this type of control method is based on a short time with maximum benefit and intangible profit, leading to customer satisfaction and maintaining producer prestige.

Another important benefits of adding an automatic inspection system for defects to a machine vision inspection include a decrease in the amount of wasted consumables and allowing a single operator to monitor more than one process at a time.

Intangible assets management has without any drought become one of the most interesting research topics in the last couple of years. Although much has been researched and published in intangible assets, still many questions remain unanswered. Perhaps a good foundation, a good starting point, in studying intangible assets would be to determine if has to do with managing knowledge or perhaps it is something more, to determine if knowledge can be managed at all in order to make the most out of a process. The management of intangible assets is the way an organization identifies and leverages knowledge in order to be competitive.

To make the most out of intangible assets is a conscious effort to get the right knowledge to the right people at the right time so that it can be shared and put into action.

It has been argued that intangible assets management is a poor term because intangible assets cannot be managed. This is because intangible assets are based on knowledge that lives primarily in the mind.

In the contemporary business environment, the competitive position of companies among others is influenced by its capability to create new knowledge which in return results in the creation of 
a competitive advantage.

An intangible asset is acquired or developed by a manufacturing company with an intent to use it in the production process to generate benefit in the future. Referring to the present paper, the competitive position lies in using an automatic visual inspection of products.

\section{References}

1. Corrado, C., Hulten, C., Siche, D., Intangible Capital and US Economic Growth, Review of Income and Wealth, Vol. 55, No. 3, pp. 661-685, http://dx.doi.org/10.1111/j.1475-4991.2009.00343.x., (2009).

2. OECD, OECD Science, Technology and Industry Scoreboard 2015: Innovation for growth and society, OECD Publishing, Paris, pp. 38, DOI: http://dx.doi.org/10.1787/sti_scoreboard-2015-en, (2015).

3. Goodridge, P., Haskel, J., Wallis, G. UK Innovation Index: Productivity and Growth in UK Industries, CEPR Discussion Papers 9063, London, (2012).

4. Niebel, T., O'Mahony, M., Saam, M. The Contribution of Intangible Assets to Sectoral Productivity Growth in the EU, ZEW Discussion Paper 13-062, Mannheim, (2013).

5. I. L. Bolundut, "Tehnologia materialelor plastice și compozite," Iași, Junimea , (2011).

6. ARBURG; Ghid de defecte de suprafață la piesele termoplaste injectate, pp. 12, http://www.arburg.com

7. Y.-C. P. Szu-Hao Huang, "Automated visual inspection in the semiconductor industry," Elsevier, pp. 2, (2014).

8. L. H. Dusan Koniar, "Virtual Instrumentation for Visual Inspection in Mechatronic Applications," Elsevier, pp. 228, (2014). 